\title{
When is it an osteoclast?
}

\author{
MICHAEL KAYE \\ From the Division of Nephrology, The Montreal General Hospital, 1650 Cedar Avenue, Montreal, Quebec \\ H3G 1A4, Canada
}

SUMMARY Using acid phosphatase as a marker, osteoclasts were examined from single sections of undemineralised iliac crest biopsies from patients with renal failure and from normal controls. Eighty one per cent of the cells from controls and $56 \%$ of the cells from patients with renal failure appeared to be non-nucleated or mononucleated. Serial sections showed, however, that $73 \%$ of the control cells were actually multinucleated as were $91 \%$ of the patients' cells. Howship's lacunae were present in similar proportions in the controls whether the cells were multinucleated or not, suggesting that they should all be classed as osteoclasts. More multinucleated cells and lacunae were present in the patients with renal failure. It is concluded that all acid phosphatase cells adjacent to bone are osteoclasts and that the presence of more lacunae and multinucleated cells in renal failure is compatible with enhanced cellular resorption.

Osteoclasts have generally been defined as multinucleated cells found in proximity to bone surfaces. With the availability of more specific markers for these cells, particularly with the acid phosphatase technique, cells which stain intensely for the enzyme but which are mononucleated have been observed.' Evans et $\mathrm{l}^{1}$ found that $62 \%$ of the stained areas were non-nucleated or mononucleated, but there is disagreement as to whether these should be classified as osteoclasts. Any attempt to quantitate these cells, as in histomorphometry, will lead to large differences depending on selection criteria. Furthermore, correlations between osteoclast numbers and variables such as parathyroid hormone concentrations will also depend on the technique used for counting osteoclasts. The present study was undertaken to find out what is or is not an osteoclast and to attempt some functional measurement of the different cell types divided according to their nuclear characteristics. In addition, since bone has been examined from normal subjects and from patients with end stage renal disease osteoclast parameters in these two groups have been compared.

\section{Material and methods}

Anterior iliac crest bone biopsy specimens taken for diagnostic (nine patients) or therapeutic purposes (seven controls) were processed as described else-

Accepted for publication 7 December 1983 where. $^{2}$ The samples were from the previously described study with all the patients having end stage renal disease. Biopsy specimens were fixed in equal quantities of $10 \%$ buffered formalin phosphate and $0.5 \%$ sucrose solution for $2 \mathrm{~h}$. They were then dehydrated in propanol and embedded in glycol methacrylate at $4^{\circ} \mathrm{C}$. Serial $2 \mu \mathrm{m}$ thick sections were cut using a Porter-Blum MT2 microtome and glass knives, stained for acid phosphatase, and counterstained with Harris's haematoxylin. From the 25th section all the red phosphatase positive areas were identified and these were then followed in both directions in the adjacent sections to determine the final nuclear state of the cell. If there were not at least 10 cells for each nuclear subdivision the procedure was repeated at the 75 th and 125 th sections, leaving $100 \mu \mathrm{m}$ between so that the same cell would not be examined twice. The presence or absence of Howship's lacunae was determined from both the initial reference section and from the first section which determined whether the cell was anuclear, mononuclear, or multinuclear, termed the final reference section. For the few cells without a nucleus the presence or absence of lacunae was assessed at both ends of the cell. A total of 92 cells from the control subjects and 214 from those with renal failure were evaluated. More cells were counted in the patients in order to have adequate numbers of mononuclear cells. Statistical analysis of differences between the groups was performed using the $\chi^{2}$ test. 


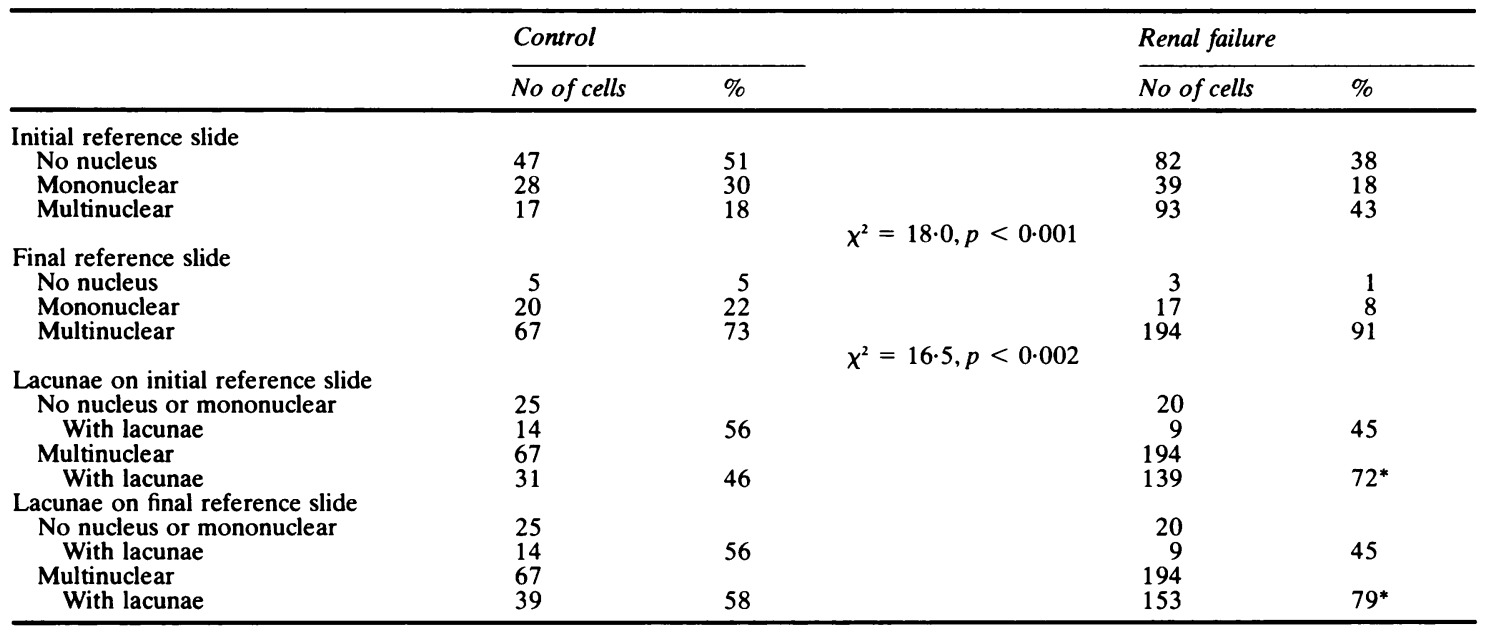

* Multinuclear cells with lacunae compared with mononuclear cells with lacunae in the renal failure group: initial and final slides $\chi^{2}=6 \cdot 0, \mathrm{p}<0.02$.

Multinuclear cells with lacunae in renal failure group compared with multinuclear cells with lacunae in the controls: initial slide $\chi^{2}=14 \cdot 1, \mathrm{p}<0 \cdot 001$; final slide $\chi^{2}=10 \cdot 1, \mathrm{p}<0.001$.

\section{Results}

On the initial reference section only $18 \%$ of the acid phosphatase stained cells from controls and $43 \%$ from patients were multinucleated (Table). The distribution of cell types was different, with the patients having more multinucleated and fewer mononucleated and non-nucleated cells.

After analysing the serial sections a considerable change became apparent, with three quarters or more of the cells being multinuclear. The difference between the renal failure and control group remained, with $91 \%$ of cells being multinuclear in the patients compared with $73 \%$ in the controls.

The number of cells with an associated Howship's lacuna on the initial and final reference section is also shown in the Table. Not all cells had lacunae and in the control group the presence of lacunae was independent of whether the cells were multinucleated or not. Seventy nine per cent of the multinucleated cells from patients with renal failure were associated with lacunae, compared with only $45 \%$ of mononuclear cells and $56 \%$ and $58 \%$ in either of the control groups.

\section{Discussion}

This study illustrates some of the difficulties in evaluating osteoclasts in histopathological material. Based on the definition of an osteoclast as a multinucleated structure, most of the cells in a single sec- tion would be excluded because the section plane shows these cells as non-nucleated and mononucleated cells despite the presence of multiple nuclei which cannot be seen without serial sections. The large size of osteoclasts, ranging from 3000-25 000 $\mu \mathrm{m}^{3}$, and the large amount of cytoplasm compared with nucleus make it unlikely that a single section will give a representative view of each cell, whereas for mononuclear cells these difficulties are not present. Clearly, use of sections where osteoclasts are not specifically stained will make their identification even more dubious and only a small fraction of the total population will be seen.'

When quantitative data are desired the results indicate that if serial sections are not used then all acid phosphatase positive cells adjacent to the bone should be considered as osteoclasts, which is in accord with the recommendations of Evans et al.' Although about two thirds of these will appear to be non-nucleated or mononucleated, when traced three quarters or more will be multinucleated. For those cells that are truly non-nucleated or mononucleated the question arises whether they have resorptive activity. The finding that at least $45 \%$ of these cells have Howship's lacunae and that the proportions with lacunae for multinucleated and mononucleated cells are similar in the control subjects indicates that these cells are functionally active and are qualitatively osteoclasts even though they contain only a single nucleus or (apparently) none at all.

Comparison of the osteoclast populations be- 
tween the controls and patients with renal failure shows a consistent trend towards more multinucleated cells and an increased likelihood that these cells will be associated with lacunae. This suggests that bone resorption at the cellular level is actually increased in these patients-a view that has not been accepted previously. ${ }^{3-5}$ The recent report ${ }^{6}$ relating multinucleation to enhanced resorption in vitro is relevant to the patients with renal failure reported here, where more multinucleated cells were present resulting in more lacunae.

I thank Dr PJ Somerville for comments which led to this study and for reviewing the manuscript and Dr J Hanley for statistical advice. Mrs J Henderson and Mrs L Malynowski provided excellent technical assistance, and Mrs $\mathrm{H}$ Esposito typed the manuscript. The Kidney Foundation of Canada provided financial support.

\section{References}

' Evans RA, Dunstan CR, Baylink DJ. Histochemical identification of osteoclasts in undecalcified sections of human bone. Mineral Electrolyte Metabolism 1979;2:179-85.

${ }^{2}$ Kaye M. Bone marrow aluminium storage in renal failure. J Clin Path 1983;36:1288-91.

${ }^{3}$ Villanueva AR, Jaworski ZF, Hitt O, Sarnsethsiri P, Frost HM. Cellular-level bone resorption in chronic renal failure and primary hyperparathyroidism. Calcif Tissue Res 1970;5:288304.

${ }^{4}$ Jaworski AGF, Lok E, Wellington JL. Impaired osteoclastic function and linear bone erosion rate in secondary hyperparathyroidism associated with chronic renal failure. Clin Orthop 1975;107:298-310.

${ }^{5}$ Krempien B, Ritz E, Ditzen K, Hudelmeier G. Uber den einfluss der niereninsuffiizienz auf knochenbildung und knockenresorption. Virchows Arch (Pathol Anat) 1972;355:354-66.

- Fallon MD, Teitlebaum SL, Kahn AJ. Multinucleation enhances macrophage-mediated bone resorption. Lab Invest 1983;49:159-64.

Requests for reprints to: Dr M Kaye, Division of Nephrology, The Montreal General Hospital, 1650 Cedar Avenue, Montreal, Quebec H3G 1A4, Canada. 